\title{
The Psychosocial Health of Shan Children in Northeast Thailand
}

\author{
NISHANT VERMA \\ Vanderbilt Clinic, Columbia University, New York, New York, USA \\ RUFINA LEE \\ New York State Psychiatric Institute, New York, New York, USA \\ CELINA SU \\ Department of Political Science, Brooklyn College, City University of New York, Brooklyn, \\ New York, USA \\ CORALIE CHAN \\ Kaiser Permanente National Program Office, Oakland, California, USA \\ PETER MUENNIG \\ Mailman School of Public Health, Columbia University, New York, New York, USA
}

\begin{abstract}
We administered the Strengths and Difficulties Questionnaire (SDQ) to 51 Shan refugee children from Burma who are living in northern Thailand, and collected life histories from 11 of their families. Of the sample, 63\% of the children were stateless, and none were Thai citizens. About 30\% of the children had normal peer relationship subscores - a number well below Thai norms after correcting for multiple comparisons $(p<.001)$. However, thier overall functioning was not different from the Thai population as a whole.
\end{abstract}

KEYWORDS

\section{INTRODUCTION}

The U.S. Committee for Refugees and Immigrants estimates that there are 13.5 million refugees and internally displaced people in the world, half of whom are under the age of 18 (USCRI, 2008; Valencia, 2001). Many of these youth

Address correspondence to Peter Muennig, MD, MPH, Mailman School of Public Health, Columbia University, 600 W. 168th St., 6th Fl., New York, NY 10032. E-mail: pm124@columbia. edu 
have been exposed to war and its consequences, including violence, death, torture, rape deprivation of basic needs, and separation from caretakers (Boothby, 1994). Child and adolescent refugees often suffer from severe psychological distress including depression, posttraumatic stress disorder, and difficulty with identity and acculturation (Pernice, 1996; Sundquist \& Johansson, 1996).

Burma (Myanmar) has waged a decades-long war against its ethnic minorities, and Thailand is the primary recipient of the refugees from this war (South, 2007). Many of those entering Thailand from Burma are stateless (without documentation of their nationality). The largest group of de facto refugees fleeing into Thailand is the Shan, at least 300,000 of whom live in Thailand (Grundy-Warr, 2002; Risser, Kher, \& Htun, 2003; Suwanvanichkij, 2008). Very little is known about their health and psychological well-being (Lang, 2002; Su \& Muennig, 2005).

\section{METHODS}

\section{Overview}

The children were drawn from three Shan communities in Northern Thailand which have been receiving basic public health and education services from two small nongovernmental organizations, the Burmese Refugee Project and Opportunity for Poor Children.

We administed the Strengths and Difficulties Questionnaire (SDQ) to all 51 children between the ages of 11 and 16 in these communities with institutional review board approval. We also conducted qualitative interviews with one family member of 11 of the sampled households.

The SDQ is a widely used screening tool widely used and has been validated amongst Thais and Southeast Asian refugees (Goodman, 1997). It is a 25-item questionnaire divided into five subscales measuring emotional, conduct, hyperactivity and inattention, peer relationship problems, and the prosocial behavior of the individual (Goodman, 2000). We were given access to the Thai normative data (Woerner, et al., 2007).

We also conducted 11 semistructured, open-ended interviews on a sample of adults to obtain a sense of the families' experiences in Burma and while immigrating to Thailand.

We used Thai normative cutoffs to determine a "normal," "borderline," or "abnormal" score. Comparison to the Thai population $(n=2,682)$ and a sociodemographically similar, matched subsample $(n=357)$ from Chiang Rai (17) was conducted with two sample $t$ tests with the Bonferonni correction for multiple comparisons. 
67 None of the parents interviewed were actively involved in firefights or ad-

68 mitted to being rape, but all were forced to carry munitions at gunpoint or

69 give a significant portion of their earnings to Burmese and/or Shan rebel

70 soldiers. All migrated from the same village in Burma through challenging

71 terrain.

72 Only $37 \%$ of the population had birth certificates, the remainder being

73 stateless (Table 1). About $12 \%$ of the population spoke only Shan, just under

74 one third were single or dual orphans, and $40 \%$ had a self-reported health

75 of "good," "fair," or "poor."

76 About $6 \%$ of the population had an abnormal total difficulty score

77 and $25 \%$ had a borderline score (data not shown). There was no sig-

78 nificant difference in any scores between Shan children born in Thai-

79 land versus Burma or between those who preferred the Shan language to

80 Thai.

81 About $70 \%$ of the Shan children showed borderline or abnormal 82 peer funcitoning, significantly more than either comparitor Thai popula-

83 tion (Table 2). In addition, the conduct and hyperactivity scales showed

84 a trend toward statistical significance. The Shan youth also showed a

85 higher rate of conduct disorders when compared with a matched rural

86 population.

TABLE 1 Baseline Characteristics of Shan Population (Continuous Variables Expressed as $M \pm S D)$

\begin{tabular}{lcc}
\hline Characteristics & Males $(n=25)$ & Females $(n=26)$ \\
\hline Age (years) & $12.8 \pm 1.59$ & $12.8 \pm 1.62$ \\
Height (cm) & $147 \pm 12.8$ & $144 \pm 7.3$ \\
Weight (kg) & $38 \pm 10.5$ & $36.9 \pm 7.3$ \\
Time in Thailand (years) & $9.7 \pm 4.3$ & $8.6 \pm 4.8$ \\
Years of Education (years) & $4.8 \pm 2.2$ & $3.7 \pm 2.1$ \\
Born in Thailand & $48 \%$ & $39 \%$ \\
Birth certificate & $45 \%$ & $31 \%$ \\
Visa/work permit & $29 \%$ & $35 \%$ \\
Speak only Shan* & $21 \%$ & $4 \%$ \\
Preferred language Shan* & $37 \%$ & $9 \%$ \\
Health status & & $4 \%$ \\
0 (poor) & $0 \%$ & $0 \%$ \\
1 (fair) & $0 \%$ & $44 \%$ \\
2 (good) & $30 \%$ & $44 \%$ \\
3 (very good) & $44 \%$ & $8 \%$ \\
4 (excellent) & $8 \%$ & $36 \%$ \\
$<2$ (parents) & $25 \%$ & \\
\hline * $<$ (0) for comparisons between males and females & &
\end{tabular}

${ }^{*} p<.05$ for comparisons between males and females. 
TABLE 2 The Difference in Mean SDQ Scores and Two Sample T-Test Comparison Between Shan Population and Thai Norms, and Norms Derived From a Subsample Of Sociodemographically Similar Youth from a Similar Rural Province (Chiang Rai)

\begin{tabular}{lcl}
\hline SDQ subscale & Difference of $M$ & $p$ value \\
\hline Thailand norms & & \\
Emotional & 0.0 & 1.0 \\
Conduct & -0.35 & 0.09 \\
Hyperactivity & 0.56 & 0.04 \\
Peer & -0.64 & $0.004^{*}$ \\
Prosocial & 0.21 & 0.21 \\
Total difficulties & -0.37 & 0.57 \\
Chiang Rai subsample norms & & \\
Emotional & -0.29 & 0.3 \\
Conduct & -0.58 & $0.008^{*}$ \\
Hyperactivity & 0.13 & 0.65 \\
Peer & -0.90 & $0.001^{*}$ \\
Prosocial & 0.41 & 0.19 \\
Total difficulties & -1.57 & 0.02 \\
\hline
\end{tabular}

Note. SDQ $=$ Strengths and Difficulties Questionnaire.

${ }^{*} p$-value remains significant after correcting for multiple comparisons within the sample or subsample category.

\section{CONCLUSION}

This study highlights the level of social difficulty amongst the Shan youth. Many of the children have lost at least one parent and some cannot adequately speak the Thai language, a critically needed skill. Nevertheless, in many of the SDQ domains, the Shan children scored similarly to their Thai contemporaries. Thus, their total difficulties scores are similar to those of Thai youth.

This study was subject to a number of important limitations. First, the community we studied may represent a "best case scenario" as they likely did not suffer as severe hardship as some other Shan children in Thailand, and they are being served by NGOs that provide basic education and health services. Second, This study was powered to detect a difference of $>.5$ at a $\beta=.8$ but not powered to detect small differences (traditionally defined as a.1 difference in means). Low power is unlikely to explain a difference in the total difficulties score; however, it may mask differences in the conduct and hyperactivity subscales.

In this study, we find reason for both hope and alarm. Hope, in that difficulties with peer interactions may be easier to repair than other domains of the SDQ, and because the children surveyed are generally well-functioning. Alarm, because this particular community is relatively well positioned for success within Thailand, but it nevertheless reveals some signs of poor physical and mental health among its youth. 
110

111

112

Boothby, N. (1994). Trauma and volence among refugee children. In T. B. A. J. Marsella (Ed.), Amidst peril and pain: The mental health and well being of the world's refugees (pp. 239-259). Washington, DC: American Psychological Association.

Goodman, R. (1997). Strengths and Difficulties Questionnaire: A research note. Journal of Child Psychol Psychiatry, 38, 581-586.

Goodman, R. (2000). Predicting type of psychiatric disorder from Strengths and Difficulties Questionnaire (SDQ) in child mental health in child mental health clinics in London and Dhaka. European Child and Adolescent Psychiatry, 9(2), $129-134$.

Grundy-Warr, C. S. Y. E. W. (2002). Geographies of displacement: The Karenni and the Shan across the Myanmar-Thailand border. Singapore Journal of Tropical Geography, 23(1), 93-122.

Lang, H. J. (2002). Fear and sanctuary: Burmese refugees in Thailand. Ithaca, NY: SEAP Publications.

Pernice, R. B. J. (1996). Refugees' and immigrants' mental health: Association of demographic and post-immigration factors. Journal of Social Psychology, 136, 511-519.

Risser, G., Kher, O. U. M., \& Htun, S. (2003). Running the gauntlet: The impact of internal displacement in southern Shan State (Vol. 2008). Bangkok, Thailand: Chulalongkorn University.

South, A. (2007). Karen nationalist communities: The "problem" of diversity. Contemporary Southeast Asia, 29(1), 55-76.

$\mathrm{Su}$, C., \& Muennig, P. (2005). The politics of social entrepreneurs in access to education: A case study of Shan Burmese refugees in Northwest Thailand. Current Issues in Comparative Education, 8(1), 31-40.

Sundquist, J., \& Johansson, S. E. (1996). The influence of exile and repatriation on mental and physical health. A population-based study. Social Psychiatry and Psychiatric Epidemiology, 31(1), 21-28.

Suwanvanichkij, V. (2008). Displacement and disease: The Shan exodus and infectious disease implications for Thailand. Conflict and Health, 2, 4.

United States Committee for Refugees and Immigrants. (2008). World refugee survey 2008 - Thailand. Retrieved from http://www.unhcr.org/refworld/docid/485 f50d6c.html

Valencia, A. (2001, June). Child refugees: Young and vulnerable. Retrieved from http://earthtrends.wri.org/features/view_feature.php?fid=26\&theme $=4$

Woerner, W., Nuanmanee, S., Wongpiromsarn, Y., Goodman, R., Becker, A., \& Rothenberger, A. (2007). Thai parent-rated Strengths and Difficulties Questionnaire (SDQ): Normative data; scale properties, and comparison with European field samples. Paper presented at the 2nd International Conference on Child and Adolescent Psychopathology. 